\title{
CAPITALISMO DEPENDENTE E EMPOBRECIMENTO INDÍGENA NO BRASIL RURALISTA ${ }^{1}$
}

\author{
Cristhian Teófilo da Silva \\ (Universidade de Brasília)
}

\begin{abstract}
Resumo: Este artigo defende que es- Abstract: This article argues that stutudos sobre as formas de desigual- dies on the forms of inequality and dade e pobreza que afetam os povos poverty that affect contemporary Inindígenas contemporâneos deve partir digenous Peoples must start from a de uma perspectiva macro-histórica e macro-historical and micro-sociologimicro-sociológica, de modo a construir cal perspective, in order to construct a uma definição de "pobreza indígena" definition of "indigenous poverty" sensensível a sua diversidade e comple- sitive to its diversity and complexity. In xidade de manifestações. Para isto order to do so, it will seek to reconcile buscará conciliar os debates sobre o the debates about dependent capitacapitalismo dependente e os proces- lism and the socioeconomic processes sos socioeconômicos de integração of integration of Indigenous Peoples dos povos indígenas a sistemas colo- into specific colonial and capitalist sysniais e capitalistas específicos atentos tems, paying attention to the fact that ao fato de que estes não se desenrola- these did not unfold in the same way in ram de modo idêntico em cada lugar e each place and over time, as evidentampouco de forma inalterada ao longo ced by studies on interethnic contact in do tempo, como atestam os estudos anthropology and ethnohistory, which sobre o contato interétnico em antro- privilege indigenous perspectives and pologia e etnohistória, que privilegiam transformations on these processes. as perspectivas e transformações indí- The article will be supported by ethgenas sobre esses processos. $\mathrm{O}$ artigo nographic contributions and denunciaestará apoiado em contribuições etno- tions of human rights violations of Indigráficas e denúncias de violação dos genous Peoples in the Southern region direitos humanos dos povos indígenas of Brazil.
\end{abstract}

nas regiões da fronteira Sul do Brasil.

Palavras-chave: Pobreza; Povos indí- ples; dependency

Key-words: Poverty; Indigenous Peogenas; dependência

\footnotetext{
1 Este artigo reproduz, parcialmente e com modificações, algumas ideias originalmente publicadas nos artigos: "Movimentos indígenas na América Latina em perspectiva regional e comparada", Revista de Estudos e Pesquisas sobre as Américas, v. 9, n.1, 2015, pp. 165-206; e "Situações coloniais, pluralismo étnico e desafios da autonomia indígena na América Latina”, Interethnic@ - Revista de estudos sobre relações interétnicas, v. 19, n. 1, 2015, pp. 3-35.
} 


\section{Introdução}

Em publicação do Banco Mundial (2015) sobre os indicadores sociais e econômicos da população indígena na primeira década do século XXI na América Latina foi observado que os benefícios decorrentes do último ciclo de políticas de redução da pobreza não foi suficiente para diminuir a desigualdade social existente entre indígenas e não-indígenas. Observou-se, inclusive, um quadro de pobreza crônica com a manutenção de expressivos percentuais de população indígena nas camadas mais pobres e de extrema miséria na região. Segundo análise dos especialistas do Banco Mundial:

(...) nos países da América Latina para os quais dispomos de dados, a proporção de famílias indígenas que vivem na pobreza ainda é o dobro das famílias não indígenas que vivem na pobreza, 2,7 vezes maior para extrema pobreza e três vezes maior para pessoas que vivem com menos de US\$1,25 por dia. (BM, 2015, p. 59)

Isto revela que as ações e políticas multiculturais deslanchadas nos anos 90 e que se beneficiaram do crescimento econômico do início do novo século tiveram um papel meramente "nominal" para reduzir a pobreza entre os povos indígenas, não chegando a fazer frente aos efeitos da exploração econômica e da degradação de recursos naturais das terras indígenas, tornando até mesmo ineficazes, em alguns casos e países, as garantias dos direitos dos povos indígenas ao território, a autodeterminação e ao etnodesenvolvimento.

Diversos estudos e pesquisas comparadas têm se debruçado sobre este problema social no mesmo período buscando mensurar padrões mundiais de empobrecimento e desigualdade, bem como políticas para sua reversão e erradicação (ver Plant, 1998; Davis, 2002; Eversole, McNeish \& Cimadamore, 2005; Hall \& Patrinos, 2006). Sem pretender revisar criticamente estes trabalhos, os quais partem corretamente da premissa de que a pobreza é uma questão, mal resolvida, de "desenvolvimento" - questionando, nesse sentido, o próprio discurso do "desenvolvimento" na esteira da contribuição de Arturo Escobar (1995) sobre a construção e desconstrução do terceiro mundo -, o aspecto central que emerge de tais estudos é a colocação da pobreza indígena como um tema de interesse internacional (ver Kumar, 2009; Sanga, 2010, entre outros). Esta ampliação da escala de interesse pelo tema resulta de agendas globais de entidades multilaterais, a exemplo do próprio Banco Mundial, Banco Interamericano de Desenvolvimento, Nações Unidas e suas agências etc., que aportam para o debate múltiplas variáveis e conceitos como participação política, capital social, direitos humanos, gênero, ambiente etc. articulados a bases de dados de países específicos.

Entretanto, no que tange à pobreza indígena, esta perspectiva internacionalista não promove, como seria desejável, o necessário diálogo com perspectivas teóricas e metodológicas precedentes - a exemplo da teoria da dependência - e de caráter antropológico - a exemplo dos estudos de contato interétnico - , que ofereceriam a vantagem de compreender a pobreza como fenômeno simultaneamente histórico e interétnico do capitalismo ao mesmo tempo que em- 
pregar as noções e categorias adequadas para a formulação compreensiva do problema.

Este texto vem defender, portanto, que o estudo das formas de desigualdade e pobreza que afetam os povos indígenas contemporâneos deve partir de uma perspectiva macro-histórica tanto quanto micro-sociológica, de modo a definirmos "pobreza indígena" em toda sua diversidade e complexidade de manifestações, i.e., observando as respostas particulares advindas das formas de resistência e acomodação a esses processos elaboradas pelos próprios povos indígenas e seus "minissistemas" para responder às frentes históricas de expansão capitalista e formação do sistema-mundo como uma nova situação histórica planetária (Wallerstein, 1979, 1984 e 1998). Entretanto, para compreender porque a pobreza indígena tem se mostrado um fenômeno histórico e interétnico com raízes nesse processo econômico global, faz-se necessário conciliar aos debates sobre o capitalismo dependente aos processos socioeconômicos de integração dos povos indígenas a sistemas coloniais e capitalistas específicos atentos ao fato de que estes não se desenrolaram de modo idêntico em cada lugar e tampouco de forma inalterada ao longo do tempo, como atestam os estudos sobre o contato interétnico em antropologia e etnohistória, que privilegiam as perspectivas e transformações indígenas sobre esses processos ${ }^{1}$. Isto significaria reconhecer que a pobreza que aflige os povos indígenas não resulta de suas culturas ou cosmologias, ou de atrasos e dificuldades para "entrar na modernidade", mas dos processos que produzem a desigualdade reiteradamente através da expropriação territorial, da segmentação étnica do mercado de trabalho e da subsequente superexploração dos trabalhadores étnica e racialmente subordinados no âmbito do capitalismo.

Nesse sentido, se os estudos da dependência culminam no reconhecimento de um padrão imperialista de poder, que tem estruturado as relações internacionais contra e em desfavor de sociedades periféricas, a consideração dos efeitos desses processos sobre povos indígenas, tribais ou nativos tem sido pouco aprofundados, em especial no que tange a responder como e porquê tal padrão de poder se reproduz no tempo e dissemina no espaço homogeneizando (leia-se empobrecendo) a situação socioeconômica de povos indígenas tão diferentes e em países tão distintos vis-à-vis as sociedades nacionais destes. Este seria um aspecto crucial para se explicar, de modo similar, como e porquê tais povos passam a se servir da consciência de sua distintividade étnica e cultural em nível mundial para realizar sua política interétnica (ver SAHLINS apud ALMEIDA, 2011; NIEZEN, 2003 e BRYSK, 1996). Estas constituem questões centrais para se compreender o surgimento dos movimentos indígenas contemporâneos que gradativamente assumem conteúdos e características ideológicas anticolonialistas, antissistêmicas e contrahegemônicas semelhantes, mesmo em áreas e regiões distintas e envolvendo povos culturalmente distintos na América Latina e no mundo (SILVA, 2016).

1 Ver Meillassoux, 1971 para a região da costa africana e Wolf 2010 [1982] para uma perspectiva mundial; mais recentemente Sunseri 2017 abordou o tema para a costa oeste dos E.E.U.U. Para o contexto latino-americano ver as contribuições da antropologia feita na região citadas mais abaixo. 
Isto posto, este capítulo visa propor argumentos para a articulação de contribuições advindas da teoria da dependência, em particular as contribuições seminais de Eric Wolf e de Ruy Mauro Marini em torno, respectivamente, da segmentação étnica do mercado de trabalho (1982) e da dialética da dependência e o conceito de superexploração (1973), e as contribuições antropológicas latino-americanas em torno do contato interétnico e a estruturação desigual das diferenças em termos étnicos e raciais dele decorrente. Argumento a favor desta articulação porque a considero imprescindível para a adequada construção de um conceito operacional de "pobreza indígena", assim como para a construção de uma correspondente abordagem que Ihe seja compreensiva antropologicamente.

Dito de outro modo, se aprendemos com as perspectivas dependentistas que o atraso, subdesenvolvimento ou pobreza dos países periféricos e semiperiféricos não pode ser creditada a suas culturas como preconiza certas "teorias da modernização", sendo, na verdade, a outra face do "desenvolvimento", o mesmo deve valer para os povos indígenas. Por outro lado, aprendemos com os estudos da mudança social e cultural junto aos povos indígenas que as dinâmicas capitalistas da sociedades periféricas e semiperiféricas impõem uma marginalização social, política e econômica a eles e seus territórios. Sendo assim, estamos diante de estudos que lidam com os mesmos processos, porém enfatizando problemáticas visíveis em escalas distintas o que, por sua vez, tem dificultado o entendimento das desvantagens sociais, econômicas e políticas enfrentadas pelos povos indígenas nas sociedades nacionais onde estão incluídos, assim como do porquê políticas multiculturalistas, dentre outras de transferência de renda, não conseguem alterar este quadro.

O conceito de superexploração se mostrará estratégico para superar esta disjunção e suscitar reflexões sobre o problema, como se espera demonstrar a partir do caso da situação de superexploração dos povos indígenas pelo chamado "agronegócio" no Brasil contemporâneo.

\section{Conciliando Teorias da Dependência e do Contato Interétnico}

Para melhor apreensão da duração histórica e regional do problema do empobrecimento indígena, devemos atentar para as lições dos estudos comparados da economia política latino-americana realizados no contexto do pós-Guerra e que adotaram o "desenvolvimento" como objeto central de pesquisa. Estes estudos nos ensinam que o "atraso" latino-americano foi resultado da manutenção do padrão de poder colonial exercido para a exploração econômica nas ex-colônias no âmbito do processo mundial de acumulação de capital do século XX. Esta manutenção ocorreu porque, ao contrário do que afirmavam as teorias das vantagens comparativas preconizadas pelo liberalismo econômico dos países centrais ao final do século XIX, o que ocorreu, conforme análise de Martins (2006), foi uma lenta e progressiva queda dos preços dos produtos primários em relação aos industriais, que se acelerava durante as crises da economia mundial. Por exemplo: "De 1876-1880 a 1911-1913, os preços dos produtos primários haviam se deteriorado em relação aos produtos industriais, caindo de um índice 100,0 para 85,8. Esse índice se deteriora ainda mais durante a crise do entre-guerras, 
alcançando 64,1 em 1936-1938". (MARTINS, 2006, p. 156)

Diante desta realidade, e ainda segundo Martins, a perda de renda dos países periféricos e as barreiras para o seu crescimento, gerando deflação e retração do consumo interno, promoveram tensões sociais que se acumularam e pressionaram movimentos revolucionários na América Latina, África e Ásia (idem, p. 157). Daí, o neocolonialismo (ao invés do pós-colonialismo, como se poderia supor) ter emergido nos estudos sobre as economias periféricas como noção crítica a um modelo socioeconômico e político de exploração decorrente da assimetria das relações econômicas internacionais, da política das nações hegemônicas ao longo do tempo, dos modelos de exploração econômico-financeira destas nações e das formas de apropriação do excedente econômico realizadas por elas (MACHADO, 1999, p. 201).

A partir desta noção, os estudos econômicos latino-americanos, a exemplo da Comisión Económica para América Latina y el Caribe (CEPAL), dedicaram-se a formular em meados do século XX, uma nova doutrina econômica para os países da região com o propósito de alavancar seu desenvolvimento, definido como "crescimento econômico de base industrial", a exemplo das sociedades capitalistas modernas. Esta doutrina visava promover, através do protagonismo do Estado nacional, uma política de industrialização dirigida com vistas à substituição das importações, o que veio a ser designado como "nacional-desenvolvimentismo". Esperava-se que esta política superasse os impasses e dificuldades que bloqueavam o desenvolvimento periférico como a industrialização espontânea, a baixa elasticidade-renda dos produtos primários, o excesso de força de trabalho rural nos países periféricos, as políticas protecionistas dos países centrais etc. Entretanto, mais importante que deter-se na doutrina, é a compreensão da realidade latino-americana que lhe serve de base que nos interessa apreender para fins de reabilitação da perspectiva dependentista para o estudo do empobrecimento indígena. Desse modo, esta compreensão nos ensina que:

Os problemas que levavam a América Latina e a periferia ao atraso derivava de heranças históricas, como a colonização, e decisões internas equivocadas que beneficiavam grupos parasitários em detrimento da nação. Estes países, ao assumirem sua condição nacional, deveriam superá-los e corrigi-los. Essa retificação não implicava um choque com estruturas internacionais, mas sim com grupos sociais e mentalidades internas. Se tratava de superar uma especialização produtiva que a longo prazo se revelou deletéria, de subordinar o tradicionalismo, ou de controlar pela austeridade as tentações ao consumo que a escassez impulsionava. As soluções variavam tal como o diagnóstico, mas tinham em comum o fato de que significavam o desenvolvimento do poder de decisão nacional: sejam elas as políticas de substituição de importação; ou a reivindicação do capital estrangeiro, visto como um recurso auxiliar, mas necessário, em maior ou menor medida, à formação e expansão da poupança e da renda nacional. A implementação destas soluções levaria à convergência com os padrões econômicos, políticos e sociais dos países centrais e ao desenvolvimento. $O$ subdesenvolvimento se explicava por um atraso na formação das dimensões econômicas, políticas, sociais e culturais que constituíam a nacionalidade, as quais uma vez estabelecidas implicavam o desenvolvimento. (MARTINS, 2006, p. 170-171) 


\section{4}

Portanto, de um problema a princípio mais econômico do que político (promover o nacional-desenvolvimentismo com uma política de substituição de importações no âmbito dos Estados nacionais, doutrina esta promovida pela CEPAL), a primeira geração de pensadores da realidade econômica latino-americana promoveram a constatação de uma questão mais política e social do que econômica: o estabelecimento de uma divisão internacional do trabalho hierarquizada constituída por classes e grupos sociais dependentes do capital estrangeiro e "herdeira histórica" de certo tipo de "mentalidade interna" colonizada.

A partir desta constatação, os estudos da economia política na região passaram a se debruçar sobre a organização política e social da interdependência econômica global, i.e., imperialismo, em detrimento dos projetos e interesses políticos nacionais na periferia do sistema mundial. Desse modo, eles buscavam explicar como o sistema mundial faz para se expandir às custas da apropriação do excedente de países que o produzem mesmo em prejuízo próprio em decorrência das "escolhas" de suas elites e burguesias dependentes. Em suma, tratava-se de explicar como era produzida e reproduzida dialeticamente (em termos marxistas) ou política e socialmente (em termos weberianos) o desenvolvimento dependente dos países latino-americanos na nova ordem econômica mundial, o que representou um "salto na compreensão da realidade latino-americana" (MARTINS, 2006, p. 170) a partir de um novo enfoque.

Este enfoque se mostrou fundamental para explicar as articulações do capitalismo global com os Estados nacionais em escala mundial e seus efeitos para a formação dos subcapitalismos característicos dos países periféricos da região. Escapou a esta perspectiva, entretanto, reconhecer que à hierarquização no plano internacional se dá igualmente (e talvez, mimeticamente) uma hierarquização nos planos nacionais acarretando a configuração de economias regionais e locais marginais e uma estratificação étnica e social da população, precisamente nos termos que noções como a de "colonialismo interno" de Pablo González Casanova (1963) pretenderam elucidar. Este efeito hierarquizador/ marginalizador das economias e mercados de trabalho regionais incide diretamente sobre a realidade dos povos indígenas, e outras populações étnica ou racialmente diferenciadas, na América Latina e Caribe, podendo ser aferido na expropriação contínua de territórios e recursos dessas populações como uma atualização constante do processo de "acumulação primitiva" que enseja formas de superexploração do trabalho a que são submetidos os expropriados que conformam sempre novas classes trabalhadoras, rurais e urbanas, racialmente segregadas em mercados que passam a se segmentar etnicamente (Wolf, 1982, p. 432).

Nestes contextos, a superexploração do trabalho, enquanto categoria central do capitalismo dependente (ALMEIDA FILHO, 2013), como a compreendeu Ruy Mauro Marini (1973), refere-se à queda dos preços da força de trabalho abaixo de seu valor de modo a regular a força de trabalho para sustentar a taxa de lucro da burguesia dependente articulada que está ao capitalismo internacio- 


\section{5}

nal. Isto significa dizer que a pobreza latino-americana seria resultado de uma forma específica de exploração, na qual, segundo Osorio (2013, p. 49), o valor da força de trabalho é violado:

Tal violação pode ocorrer por diversos mecanismos, seja no mercado - no momento de sua compra e venda -, seja no próprio processo de trabalho - por um desgaste "anormal, extensivo ou intensivo. Em todo caso, o salário recebido já não é equivalente ao valor da força de trabaIho, não cobre seu valor diário ou seu valor total. (OSÓRIO, 2013, p. 49)

No que concerne aos povos indígenas temos que esta relação de violação é permitida e intensificada em decorrência das características específicas que assume o capitalismo dependente em sociedades plurais que promovem a subalternização dos povos indígenas através dos assaltos a sua autonomia logrados com a expropriação de suas terras e inferiorização de suas identidades e culturas, em especial quando os classificam pela categoria colonial de "índios". Esta esfera do problema ainda se mostra pouco abordada nos estudos sobre dependência que desconsideram o papel dos povos indígenas, seus territórios e minissistemas como parte do processo e do problema histórico de expansão civilizatória do capitalismo.

Como bem analisou Aníbal Quijano, o resultado desse processo/problema é a globalização de uma forma padronizada de exercer o poder em nível mundial que possui um conteúdo intrinsecamente colonial. A "colonialidade do poder" como padrão de poder mundial, ainda que o seja de modo mais característico nos países americanos, serve-se da ideia de "raça" como fundamento de classificação social e legitimação da exploração capitalista, onde o Estado opera como forma de controle da população subalternizada. (Quijano, 2002, p. 04)

A partir destas lições recentes, se os estudos dependentistas acertaram ao elucidar o modo como distintos ciclos econômicos e formas de superexploração do trabalho são tecidas em um jogo de poder e ideologias que organizam grupos econômicos e setores produtivos da sociedade e os articulam a outros grupos e setores dominantes no sistema mundial, eles parecem ter se detido ante a análise, necessária, de como o poder se impõe e legitima a partir destes grupos sobre populações que são excluídas e subordinadas ao horizonte ideológico dos primeiros, o que vem a ser a contribuição seminal de Quijano para o debate e para o estudo da dominação interétnica.

Entretanto, se o enfoque dependentista se mostrou limitado para apreender o processo de hierarquização e segregação racial na divisão internacional do trabalho, outros estudos, como aqueles sobre as frentes de expansão capitalista e o contato interétnico delas decorrente, acabaram por lhes servir de complemento. Conceitos de "colonialismo interno" (González Casanova, 1963); "regiones de refugio" (Aguirre Beltrán, 1991 [1967]), "fricção interétnica" (Cardoso de Oliveira, 1981 [1964]), "transfiguração étnica" (Ribeiro, 1970 - lembrando que seus estudos foram realizados nos anos 50) e "etnodesenvolvimento" (Bonfil 
Batalla et. al., 1982), por exemplo, expressam o intenso e articulado trabalho intelectual promovido por sociólogos e antropólogos latino-americanos diante dos processos de mudança, discriminação e exploração a que estavam submetidos os indígenas na região desde o período colonial até a segunda metade do Século XX. Nesse sentido, e conforme análise de Roberto Cardoso de Oliveira (1998, p. 41), o binômio colonialismo - colonialismo interno foi decisivo para a mudança de foco da investigação monográfica sobre tal ou qual etnia, tal como realizado pela antropologia funcionalista britânica, para o seu entorno.

Tratou-se de uma guinada marxista no âmbito da antropologia para pensar a realidade de contato interétnico na América Latina combinada a outras perspectivas teóricas da antropologia social, cultural e mesmo hermenêutica, todas decisivas para a elaboração de conceitos que abordassem o caráter assimétrico, conflitivo e total das mudanças acarretadas para os povos indígenas na região. Todos os autores mencionados concordam em suas abordagens que os padrões de exercício do poder sobre os povos indígenas foram herdados dos regimes coloniais pelos Estados nacionais na América Latina, engendrando sociologicamente situações virtualmente disruptivas das instituições tribais e indígenas com vistas a sua subsunção política em sistemas de exploração econômica. E, mais além de simplesmente problematizar a situação colonial imposta aos povos indígenas, o que se buscava era construir formas de superação desta situação, em particular de suas manifestações contemporâneas decorrentes de planos, projetos e programas nacionais "desenvolvimentistas", como a própria noção de etnodesenvolvimento buscava promover.

Entretanto, se tais contribuições se mostraram profundas para aprendermos a considerar o colonialismo como condição para expansão do capitalismo, elas se provaram limitadas para esmiuçar como o capitalismo, em toda sua diversidade, se reproduz como uma forma potente de neocolonialismo. A ênfase dada aos projetos de vida e resistência cultural dos povos indígenas, em particular às ideologias étnicas constituídas pelas dinâmicas do contato, limitaram o debate teórico sobre a estruturação do capitalismo dependente a partir da expropriação de territórios indígenas e superexploração de sua força de trabalho, ambos pilares da produção da pobreza indígena, por mais que este fosse um aspecto empiricamente descrito e analisado no âmbito etnográfico.

Sendo assim, o enfoque dependentista se mostrou limitado em sua linguagem teórica por uma visão homogeneizadora da diversidade étnica como "classe trabalhadora" ou "exército de reserva", enquanto os estudos do contato interétnico se mostraram limitados a uma visão micro-sociológica, principalmente, pela ênfase dada às instituições de fronteira na qualidade de "agências e agentes de contato" como são as frentes de atração, os postos indígenas, a força militar e policial, os barracões de comércio, as missões, as fazendas etc. A perspectiva etnográfica nestes casos se restringiu a observar os processos de "mudança", seja social ou cultural, no "interior" das comunidades e aldeias indígenas, ocasionado por estas agências e agentes de contato, o que ensejava uma preocupação moral e política com a sobrevivência mesma destas populações (Ramos, 


\section{7}

2011), porém alheia aos processos e conexões extra locais e regionais que (re) produzem sociologicamente e economicamente a situação observada.

Para superar esta dupla limitação faz-se necessário resgatar a contribuição de Eric Wolf em seu livro: "Europe and the People Without History" ("Europa e a gente sem história"), publicado em 1982. A leitura desta obra, informado pelo debate posto acima, permite conciliar os pontos cegos que as perspectivas dependentistas (de origem marxista) e "contatualistas" (de fundo antropológico) vinham estabelecendo até aqui em torno da segmentação mundial da força de trabalho em termos raciais, de um lado, e o papel ativo que tiveram sociedades indígenas e grupos étnicos, de grande ou pequena escala demográfica, no estabelecimento da globalização moderna, na qual o capitalismo emergiu como a principal ideologia de desenvolvimento, por outro.

O trabalho de Wolf, mesmo publicado no início dos anos 80 do século XX, se mostra, sob vários aspectos, exemplar e raro para a compreensão tanto dos modos como sociedades indígenas e comunidades tradicionais são transformadoras e se transformam em sua interação com fluxos globais de trocas, quanto como sociedades plurais se constituem e organizam a partir da segmentação étnica do mercado de trabalho, que emprega rotas e circuitos globais de trocas de objetos, mercadorias, técnicas e pessoas para sua reprodução e produção de "riquezas", com impactos avassaladores no esgotamento de recursos naturais, sociedades e trabalhadores.

As sociedades plurais assim constituídas transformam populações (i.e., grupos étnicos, sociais, linguísticos, culturais etc.), anteriormente autônomos, em classes trabalhadoras (desterritorializadas, desplazadas, migrantes etc.), repositórios de força de trabalho para os empreendimentos capitalistas, nas quais:

"Indians" and "Negroes" are thus confined to the lower ranks of the industrial army or depressed into the industrial reserve. The function of racial categories within industrial capitalism is exclusionary. They stigmatize groups in order to exclude them from more highly paid jobs and from access to the information needed for their execution. They insulate the more advantaged workers against competition from below, making it difficult for employers to use stigmatized populations as cheaper substitutes or as strikebreakers. Finally, they weaken the ability of such groups to mobilize political influence on their own behalf by forcing them back into casual employment and thereby intensifying competition among them for scarce and shifting resources (...). (WOLF ,1982, p. 381)

Esta contribuição de Wolf (ele próprio um leitor de André Gunder Frank) complementa as interpretações dos estudos sobre a dependência e o neocolonialismo na América Latina ao adotar uma perspectiva marxiana e antropológica para explicar como o capitalismo se produz e perpetua na economia política desta e outras regiões articulada a povos e grupos étnicos locais, de nativos ou 
de imigrantes. É a partir destas contribuições que se faz possível enunciar a conciliação das teorias da dependência e contatualistas para definição da pobreza/ empobrecimento indígena em termos do processo histórico de expropriação e integração subordinada e desigual dos povos indígenas aos mercados de trabaIho locais, etnicamente segmentados, com vistas a torná-los e a seus territórios "fatores de produção" (sobretudo terra e trabalho) do capitalismo dependente regional.

O setor agropecuário brasileiro nas novas áreas devastadas ecologicamente de monocultura (soja, milho e algodão, dentre outros cultivos) se mostra um caso particularmente elucidativo da importância de enfoques que partam de perspectivas sócio-históricas do sistema-mundo conciliadas a estudos micro-sociológicos de povos indígenas e tradicionais de modo a observar os processos em curso de reprimarização das exportações da economia e ascensão de uma elite "ruralista", que surge articulada com velhas elites agrárias, atualizando ciclos de expropriações e superexploração dos povos indígenas, entre outras populações rurais negras e tradicionais, para atender demandas por commodities agrícolas no mercado asiático, estadunidense e europeu.

Este segmento "ruralista", que conta com bancada expressiva no Congresso Nacional, tem sido diretamente responsável pela (re)concentração fundiária com vistas à produção de produtos agropecuários, assim como tem pressionado por mudanças legislativas que retrocedem o reconhecimento de direitos de povos indígenas, quilombolas e populações tradicionais, além de promoverem alterações e retrocessos na legislação de proteção ambiental, dentre outras questões.

Apresento a seguir, apoiado em contribuições etnográficas e denúncias de violação dos direitos humanos dos povos indígenas, de que modo a expansão de monoculturas agrícolas na região Sul do Brasil serviriam como justificativa para uma abordagem compreensiva do empobrecimento indígena a partir de perspectivas dependentistas e contatualistas.

\section{A (Re)Produção da Pobreza Indígena no Brasil Ruralista}

O que os estudos acima mencionados permitem compreender é a longa história que acompanha a transformação dos países latino-americanos em economias periféricas, os territórios indígenas em áreas marginais destas economias e os povos indígenas em força de trabalho superexplorada nas áreas e regiões por eles ocupadas tradicionalmente. Este processo, de início, envolveu os povos indígenas em reelaborações e reinterpretações de sua geopolítica intertribal em função de novas alianças interétnicas com comerciantes, militares, religiosos e colonos europeus, e depois, também, com segmentos provenientes da própria sociedade colonial (ver FERREIRA, 2011 \& FERREIRA s/d). Diante de novos contextos de relações interétnicas e intertribais, perturbado por guerras 


\section{9}

e epidemias e por novas situações ou arranjos de distribuição de poder, políticas de colonização constituíram o golpe derradeiro sobre a autonomia indígena em diferentes momentos e lugares, acompanhando as sucessivas frentes de expansão das economias nacionais periféricas. Neste périplo, as fazendas, garimpos, companhias, barracões, missões, presídios e fortes militares alteraram muito pouco seu papel de entrepostos de fronteira da administração colonial em seus propósitos de assegurar a exploração econômica das nações latino-americanas em construção.

Sendo assim, quando observados desde a perspectiva histórica da economia política das economias dependentes conjugada à perspectiva micro da antropologia das relações interétnicas, o caráter regional quase uniforme do tratamento desigual dispensado aos povos indígenas pelos Estados nacionais passa a ser evidenciado à medida que se reconhece o mecanismo de auto-reprodução da dependência pela expansão territorial expropriadora promovida pelo modo de produção capitalista que reproduz, também desse modo, as condições para promover a discriminação racial, a superexploração e a segmentação étnica do mercado de trabalho de sociedades profundamente transformadas pelo contato. Nota-se, em outras palavras, o modus operandi da colonialidade do poder nas relações interétnicas em áreas de novas fronteiras agrícolas no Brasil e países vizinhos.

A título de ilustração, cabe citar os estudos históricos e antropológicos realizados por Carla Villamaina Centeno (2002), sequenciados por Antonio Brand e Eva Maria Luiz Ferreira (2009), que descrevem o modo como as relações de trabalho nos ervais da fronteira sul, no final do século XIX, prefiguraram as relações atuais de superexploração e escravidão por dívida vida pelos povos indígenas da região. Tratava-se de um regime de trabalho negligenciado como tal pela historiografia e etnografia que, muitas vezes se apoiavam no senso de comum de "escassez de mão-de-obra" na região (a mão-de-obra indígena sequer era contabilizada como tal, apesar de ser explorada) ou no preconceito com relação à aversão das culturas indígenas ao trabalho (entendido aqui em termos estritamente capitalistas). Para corrigir esta lacuna, o que Centeno demonstra a partir de farta documentação é que a presença indígena se fazia notar através de forte oposição e resistência à instalação dos ervais em seus territórios. Esta resistência foi sendo dobrada e vencida por empresários capitalistas através do endividamento de indígenas provenientes do Paraguai que se tornaram insubstituíveis no plantio da erva (Centeno, 2002, p. 321) e que viabilizaram a divisão do trabalho e a "comodificação" da erva mate num sistema de monopólio sob domínio da Companhia Matte Larangeira (BRAND \& FERREIRA, 2009, p. 109).

Já no início do século $X X$, este domínio começa a encontrar outra forma de resistência, desta vez, por parte de colonos em áreas arrendadas que começam a fragmentar as terras da Companhia, porém preservam as relações desiguais de trabalho com os povos indígenas. Este período coincide com a chegada dos gaúchos ao sul do estado do Mato Grosso, território ancestral dos Guaranis 


\section{0}

e Kaiowás, entre outros grupos migrantes minoritários, como os mineiros, onde todos prosseguem se servindo da força de trabalho de indígenas subjugados em seus próprios territórios. Segundo a descrição de Brand \& Ferreira:

O início da década de 1970 foi marcado pela chegada da segunda leva de gaúchos no antigo sul de Mato Grosso, em busca de terras que eram de custo inferior às encontradas em seu Estado de origem. Esses migrantes introduziram o cultivo da agricultura mecanizada, principalmente da soja e de novas espécies de gramíneas nas pastagens. Essa nova forma de ocupação econômica perdura até os dias atuais. Vale recordar que, com o fim do monopólio da Companhia Matte Larangeira, outras atividades na região utilizaram mão de obra indígena. Dentre essas atividades, Brand (1997) destaca a coleta de palmito, a derrubada das matas e roçada de pastos, a abertura de fazendas e de estradas. E, finalmente, a partir da década de 1980, o plantio e colheita de cana de açúcar nas usinas de produção de açúcar e álcool.

O mesmo autor conclui que a partir da mecanização, depois da década de 1970,

a presença de famílias e mesmo de aldeias indígenas, nos "fundos das fazendas", passa a representar um "incômodo" para os fazendeiros. Antes, enquanto contribuíam na derrubada das matas e na formação das fazendas, essa presença indígena era útil e não incomodava. É importante destacar que a mobilização de algumas comunidades indígenas, expulsas de suas terras no decorrer do processo de colonização do seu território, em torno da reivindicação da posse dessas terras - além daquelas que já haviam sido reconhecidas pelo SPI - Serviço de Proteção aos Índios -, levou também os proprietários a mobilizarem-se e tentarem expulsar essas famílias e comunidades. Os proprietários acreditavam que o lugar do indígena limitava-se às re-servas já demarcadas pelo SPI (BRAND, 1997, pp. 112-113)

É, portanto, sobre processos históricos de colonização, conformadores de economias dependentes, que se estruturam as relações interétnicas e padrões de superexploração indígenas atuais, com repercussões visíveis sobre seus direitos territoriais e fundamentais. A partir de informações e denúncias reunidas pelo Relatório do Grupo de Trabalho sobre os Direitos dos Povos Indígenas e das Comunidades Quilombolas da Região Sul (CNDH, 2017), é possível verificar a permanência deste regime histórica de exploração do trabalho indígena e sobre como ele reproduz as condições de pobreza desta população. O Grupo de Trabalho atuou numa região onde se encontram reservas destinadas aos povos indígenas desde o final da primeira década do século XX, com áreas coincidentes com a explorada pela Companhia Matte Larangeira. Estas reservas constituem uma fração ínfima de seus territórios originais e visavam sedentarizar indígenas para fins de sua transformação em força de trabalho através do endividamento, como visto mais acima, bem como afastá-los das áreas 


\section{1}

de interesse econômico ou expansão capitalista. Trata-se da região onde vivem hoje, sobretudo Kaingang (terceira maior população indígena do país, com mais de 33 mil pessoas), Guaranis (Nãndeva ou Avá-Guarani com aproximadamente 13 mil pessoas, Xokléng ou Laklanõ (com 1.853 pessoas) e os Xetá (com 86 membros).

Todos esses povos, dentre outros destruídos em decorrência de séculos de colonização, estabeleceram contatos com frentes colonizadoras desde os fins do século XVIII, quando se inicia a longa história de conflitos intra e intertribais, aldeamentos missionários, expropriações para fins de assentamento de colonos, exploração agropecuária - em particular da erva mate e madeireiras - e obras de infraestrutura, rodovias, ferrovias, portos e geração de energia, a exemplo da hidrelétrica binacional de Itaipu, culminando em uma longa história de conflitos, deslocamentos compulsórios e políticas de sedentarização e assimilação que visavam "resolver o problema indígena". (CNPH, 2017, p. 12)

Atualmente, os povos indígenas da região Sul constituem uma população de pelo menos 78.773 pessoas. Destas, 39.427 residem em terras indígenas. As terras indígenas regularizadas na região Sul, entretanto, perfazem um percentual de apenas $0,1 \%$ da superfície da região administrativa dos três estados da região (Rio Grande do Sul, Santa Catarina e Paraná). Nesse sentido, a forte presença indígena hoje em dia nas áreas urbanizadas é indicativa da escassez de acesso e condições de sobrevivência nas reservas e terras indígenas (Dal'ligna, 2014 \& Rodeguero, 2016), o que pressiona pela prática das "retomadas". (CNPH, 2017, p. 12) Estas, por sua vez, são criminalizadas por empresários do agronegócio na região, os quais vem articulando uma eficiente frente de resistência ao reconhecimento dos direitos territoriais dos povos indígenas, promovendo ações que primam pela violência e racismo associada à precariedade das políticas indigenistas e fragilização dos órgãos estatais responsáveis pela promoção dos direitos dos povos indígenas.

De acordo com o relatório do Grupo de Trabalho, o qual percorreu aldeias em áreas de fronteira agrícola na região, em especial próximas à faixa de fronteira internacional:

(...) observa-se nas últimas décadas que o reconhecimento e proteção dos direitos dos povos indígenas na região Sul encontra-se antagonizado sobretudo por grupos organizados do agronegócio brasileiro mobilizados a partir de uma ampla bancada autodesignada "Frente Parlamentar Agropecuária" (FPA) e conhecida como "bancada ruralista", que soma 169 parlamentares em exercício (entre deputados e onze senadores), tendo como coordenador principal o deputado federal Luís Carlos Heinze (PP/RS), contra uma minoria populacional que são os povos indígenas. As ações e movimentações contrárias aos direitos territoriais dos povos indígenas provenientes do setor agropecuário e da FPA deveriam obrigar governos e instituições públicas a aplicar rigorosamente as leis e procedimentos administrativos vigentes de regularização fundiária e gestão territorial, sobretudo porque os interesses econômicos de grandes agropecuaristas, somados ao das empresas dos mais diversos setores produtivos (exemplo, apresenta uma crescente queda no número de pequenas 
propriedades cedendo terreno para estabelecimentos com mais de miIhectares que ocupavam mais de $86,27 \%$ do total de estabelecimentos do estado já na década de 90 . A crescente concentração fundiária em áreasde redução no número de pequenos estabelecimentos gera a impressão de uma competição por terras entre pequenos agricultores e colonos eindígenas, quando, na verdade, as terras dos pequenos proprietáriostem sido transferidas regularmente nas últimas décadas para grandesproprietários particulares ou empresariais do agronegócio, os quais contribuem para a composição de uma bancada parlamentar expressiva nas esferas municipal, estadual e federal. (CNDH, 2017, p. 14-16)

A partir destas informações pode-se inferir que o número crescente de lutas por "retomada" de terras pelos povos indígenas na região é indicador do intenso processo de concentração fundiária que se agrava com a paralisação da destinação de áreas agricultáveis para os indígenas, isto em um quadro de redução de pequenas propriedades e recolonização por grandes propriedades de monocultura de soja, milho, cana-de-açúcar e algodão. Este cenário tem feito aumentar os casos de conflito interétnico no campo acentuando o já secular êxodo indígena de seus territórios e sua consequente pauperização como "classe trabalhadora" racialmente discriminada e desvalorizada. Trata-se de um processo que transfigura Guaranis e Kaingangs, dentre outros, em "índios" e, como tais, passam a ser superexplorados como "bugres", "peões" ou "paraguaios" até sua recategorização pelos agentes estatais como "escravos contemporâneos".

É a partir de processos como este que tem se dado a "reprimarização" da economia brasileira pela nova elite "ruralista". Trata-se da (re)funcionalização da economia dependente como provedora de alimentos para os países industrializados centrais através da superexploração da força de trabalho em mercados etnicamente segmentados. Não sendo possível retomar inteiramente a já conhecida contradição exposta por Marini em torno das condições que permitem às economias dependentes exercer esta função através da obtenção de mais-valia obtida com a superexploração dos trabalhadores ao invés de obtê-la pela produção de excedentes (MARINI, 2008 [1973]), o que importa ressaltar para os objetivos deste trabalho é precisamente o efeito indireto das demandas por produtos primários em nível mundial como estruturantes de processos regionais e locais de expropriação fundiária e segregação étnica de populações indígenas.

O que está em curso no caso descrito acima seria um novo processo de transferência de terras indígenas para grandes proprietários agrícolas implicando a perda de autonomia socioeconômica dos povos indígenas segundo seus usos e costumes em territórios já drasticamente reduzidos e redefinidos administrativamente como terras indígenas. Este processo já é bastante conhecido e analisado pelas perspectivas teóricas acima mencionadas. O que cabe compreender a partir da conciliação destas é como se dá, na prática, a manutenção do empobrecimento dos indígenas pari passu como insumo à conformação de um novo mercado agronegocista. Dito de outro modo, o que cabe conhecer é como 


\section{3}

se mantém, hoje em dia, a condição subordinada dos indígenas em uma era de reconhecimento de direitos à autodeterminação e aos territórios ancestrais. A violência e a política do terror, ontem e hoje, conjugada à impunidade e apoio estatal persistem como hipótese historicamente constituída para explicar o fenômeno na contemporaneidade.

Neste contexto, os indígenas se veem diante de duas alternativas: persistir na luta secular e cosmologicamente orientada pela terra através da defesa da autodeterminação, a qual Ihes concede direitos originários, mas lhe nega participação simétrica no mercado agropecuário acarretando uma economia de subsistência complementada pela venda de artesanato em centros urbanos, ou assimilar-se pelo trabalho em condições de superexploração análogas à escravidão, lembrando não se tratar aqui do trabalho escravo, histórico e colonial, propriamente dito - o que seria contraditório à lógica da superexploração, como antevisto por Marini -, mas da escravidão contemporânea como sinônima de superexploração e endividamento. O superexplorado indígena, nesse sentido, é justamente o Kaingang/Guarani/etc. transfigurados em "índios" para serem explorados como "pobres".

Diante do poder político acumulado pela nova elite ruralista, que investe no retrocesso dos direitos territoriais conquistados pelos movimentos indígenas e pela sociedade civil organizada, a primeira alternativa mostra-se cada vez menos viável, (re)produzindo o empobrecimento indígena como fenômeno de longa duração na sociedade brasileira.

\section{Considerações Finais}

É evidente que os povos indígenas não lidaram e não lidam com estes processos de modo passivo e idêntico. Tudo muda de uma aldeia para outra, que dizer, de uma parte do mundo para outra. Os modos diversos como os movimentos indígenas procuraram, desde o período colonial e ao longo do século $\mathrm{XX}$, assegurar sua autodeterminação e autonomia culminou no comprometimento, no final do século, das comunidades políticas dos Estados nacionais com o reconhecimento de seus direitos coletivos aos territórios tradicionais a partir de perspectivas multiculturalistas.

Dito de outro modo, os indígenas passaram a ser reconhecidos como sujeitos coletivos de direitos e cidadãos plenos na maioria dos países do continente (Stavenhagen, 2009) e desconstruir esta legitimidade estabelecida tanto nacional quanto internacionalmente não é tarefa fácil, mesmo para grupos de interesse do agronegócio expressivamente presentes em diversos países. A realidade dos direitos territoriais dos povos indígenas somente se mostrou possível em decorrência dos sucessivos movimentos indígenas, aliados a segmentos organizados da sociedade civil e da comunidade política, assim como utilizando o sistema internacional de direitos humanos, terem obrigado os governos locais, regionais e nacionais a reconhecer o direito de existirem como coletividades culturalmente diversas no interior destes países. Tratou-se de uma verdadeira política cultural 


\section{4}

antirracista acionada pelos movimentos indígenas junto aos Estados nacionais (ver ALVAREZ, ESCOBAR E DAGNINO, 2000; WARREN E JACKSON, 2002; POSTERO E ZAMOSC, 2005; OLIVEIRA, 2008).

Entretanto, desde o reconhecimento em âmbito nacional e mundial dos direitos dos povos indígenas, nos anos 80 e 90, e agora, os fatores que teriam propiciado as reformas constitucionais na América Latina em prol dos povos indígenas ainda não se provaram efetivos diante do poder estruturante do modo de produção capitalista (WOLF, 1999) e os grandes projetos de exploração econômica que visam sua expansão. Em verdade, como mencionado no início deste capítulo, os atuais indicadores das condições de sobrevivência física e cultural dos povos indígenas na América Latina, neste início de século, apontam para a persistência da pobreza entre estas sociedades.

Este breve ensaio vem pronunciar-se em favor de estudos e pesquisas que dediquem-se a explicar as causas estruturais do empobrecimento indígena como fenômeno global, porém produzido segundo processos locais e regionais de expropriação, segmentação étnica do mercado de trabalho e superexploração. Faz-se premente a elaboração de projetos multilocais e bifocais, tais como prenunciados por George Marcus nos idos de 1991, i.e., que consigam explicar os problemas sociais - e, em particular, os problemas sociais indígenas como a pobreza - pela conciliação do que aprendemos analisando friamente o capitalismo em nível global com as experiências concretas vividas e narradas sob sua dominação no chão das aldeias.

\section{REFERÊNCIAS:}

AGUIRRE BELTRÁN, Gonzalo. “I. Proceso Dominal”. Regiones de Refugio: EI desarrollo de la comunidad y el proceso dominical en mestizoamérica. México: Universidad Veracruzana/Instituto Nacional Indigenista/Gobierno del Estado de Veracruz/FCE, 1991 [1967].

ALMEIDA FILHO, Niemeyer. Desenvolvimento e dependência. Cátedra Ruy Mauro Marini. Brasília: IPEA, 2013.

ALVAREZ, Sonia; DAGNINO, Evelina \& ESCOBAR, Arturo (orgs.). Cultura e política nos movimentos sociais latino-americanos. Belo Horizonte: Editora UFMG, 2000.

BANCO MUNDIAL (Grupo). América Latina Indígena no Século XXI: A primeira década. Washington, D.C.: World Bank, 2015. [Disponível em: http:// documents.worldbank.org/curated/pt/603241467994679041/pdf/98544-WP-P148348-Box394854B-PUBLIC-America-Latina-Indigena-PORTUGUESE.pdf , acessado em 21/08/17]. 


\section{5}

BERNO DE ALMEIDA, Alfredo Wagner. "Os movimentos indígenas e a autoconsciência cultural - diversidade linguística e identidade coletiva". Raízes, v. 33, n. 1, jan-jun/2011.

BONFIL BATALLA, Guillermo. "El pensamiento político de los índios en América Latina". Anuário Antropológico/79. Rio de Janeiro: Tempo Brasileiro, 1981.

BRYSK, Alisson. "Turning Weakness into Strengh: The Internationalization of Indian Rights". Latin American Perspectives, Vol. 23, Issue 2, 1996.

CARDOSO DE OLIVEIRA, Roberto. "Introdução: A noção de fricção interétnica”. O índio e o mundo dos brancos. Brasília: Editora Universidade de Brasília, 1981 [1964].

CENTENO, Carla Villamaina. "As relações de trabalho na fronteira sul de Mato Grosso: A escravidão por dívidas na exploração da erva-mate”. Dimensões, vol. 14, 2002.

CONSELHO Nacional de Direitos Humanos/CNDH. Relatório do Grupo de Trabalho sobre os Direitos dos Povos Indígenas e das Comunidades Quilombolas da Região Sul. Brasília, D.F., 2017.

DALL'IGNA, Marta Beatriz dos Santos. "Entre a aldeia e a cidade: 0 trabalho na perspectiva dos índios Guarani e Kaingang do Sudoeste do Paraná na luta pela sobrevivência". Humanit., Sci., Linguist., Lett., Arts., Ponta Grossa, 22 (1), pp. 85-98, jun./jul., 2014.

DAVIS, Shelton. "Indigenous Peoples, Poverty and Participatory Development: the Experience of the World Bank". In: SIEDER, Rachel (ed.) Multiculturalism in Latin America. Institute of Latin American Studies, 2002.

ESCOBAR, Arturo. Encountering Development: The Making and Unmaking of the Third World. Princeton and Oxford: Princeton University Press, 1995.

EVERSOLE, Robyn; MCNEISH, John \& CIMADAMORE, Alberto (eds.). Indigenous Peoples and Poverty: An International Perspective. London: Zedbooks, 2005.

FERREIRA, Andrey Cordeiro. "Dialéticas coloniais: A construção do Estado e as transformações da organização social indígena sul-americana". RBCS, Vol. 26, $n^{\circ} 77$, outubro/2011. 
FERREIRA, Andrey Cordeiro. "Trabalho, alteridade e acumulação flexível: A dialética entre reestruturação produtiva e organização social indígena nas frentes de expansão da agroindústria canavieira". Trabalho apresentado no GT 18 - Reestruturação produtiva, trabalho, dominação social”. Mimeografado, s/d.

FERREIRA, Eva Maria Luiz \& BRAND, Antonio. "Os Guarani e a Erva Mate”. Fronteiras, Dourados, MS, V. 11, n. 19, pp. 107-126, jan./jun., 2009.

GONZÁLEZ CASANOVA, Pablo. "Sociedad plural, colonialismo interno y desarrollo". América Latina, ano 6, n³ 3, 1963.

HALL, Gillette \& PATRINOS, Harry Anthony. Indigenous Peoples, Poverty and Human Development in Latin America. Palgrave MacMillan, 2006.

KUMAR, Kamlesh. Review (2009): Poverty as a Global Issue: Robyn Eversole, John-Andrew McNeish and Alberto D. Cimadamore, eds, Indigenous Peoples and Poverty: An International Perspective. London: Zed Books, 2006, 311 pp. Available at: http://journals.sagepub.com/doi/pdf/10.1177/02685809090 240020902

MACHADO, Luiz Toledo. “A teoria da dependência na América Latina”. Estudos Avançados 13 (35), 1999.

MARCUS, George. “Identidades passadas, presentes e emergentes: Requisitos para etnografias sobre a modernidade no final do século $\mathrm{XX}$ ao nível mundial". Revista de Antropologia, USP, n. 34, 1991.

MARINI, Ruy Mauro. "Diléctica de la dependencia” (1973). América Latina, dependencia y globalización. Fundamentos conceptuales. Bogotá: Siglo del Hombre-CLACSO, 2008.

MARTINS, Carlos Eduardo. "O pensamento latino-americano e o sistema mundial”. In: LEVY, Bettina (comp.). Crítica y teoria en el pensamento social latinoamericano. Buenos Aires: CLACSO, 2006.

MEILLASSOUX, Claude. The development of indigenous trade and markets in West Africa. 1971.

NIEZEN, Ronald. “A New Global Phenomenon?”. The Origins of Indigenism: Human Rights and the Politics of Identity. Berkeley/Los Angeles/London: University of California Press, 2003.

OLIVEIRA FILHO, João Pacheco de. "O Nosso Governo": Os Ticuna e o re- 


\section{7}

gime tutelar. São Paulo: Marco Zero; Brasília: MCT/CNPq, 1988.

OSORIO, Jaime. "Fundamentos da superexploração". In: ALMEIDA FILHO, Niemeyer. Desenvolvimento e dependência. Cátedra Ruy Mauro Marini. Brasília: IPEA, 2013.

PLANT, Roger. Issues in Indigenous Poverty and Development. Washington, D.C.: IADB, December 1998, No. IND-105. [Disponível em: https://publications. iadb.org/bitstream/handle/11319/4574/Issues\%20in\%20Indigenous\%20Poverty\%20and\%20Development.pdf?sequence=1\&isAllowed=y , acessado em 21/08/17]

POSTERO, Nancy Grey \& LEON ZAMOSC (eds.). La lucha por los derechos indígenas en América Latina. Quito: Abya-Yala, 2005.

QUIJANO, Aníbal. "Colonialidade, poder, globalização e democracia". Novos Rumos, Ano 17, n 37, 2002.

QUIJANO, Aníbal. "Colonialidade do poder, eurocentrismo e América Latina". Buenos Aires: CLACSO, 2005. Disponível em: [http://bibliotecavirtual.clacso.org.ar/clacso/sur-sur/20100624103322/12_Quijano.pdf] Acessado em 13 de novembro de 2014.

RAMOS, Alcida Rita. "A antropologia brasileira no mundo". In: RIBEIRO, Gustavo Lins; FERNANDES, Ana Maria; MARTINS, Carlos Benedito \& TRAJANO FILHO, Wilson (orgs.). As ciências sociais no mundo contemporâneo. Brasília: Letras Livres/EdUnB, 2011.

RIBEIRO, Darcy. Os índios e a civilização. Rio de Janeiro: Civilização Brasileira, 1970.

RODEGUERO, Miriam. "O frigorífico na aldeia: Algumas implicações do trabalho nas indústrias de carne para os Kaingang do Toldo Chimbangue”. PPGCS-UFJF, v. 11, n. 2, jul./dez., 2016.

SANGA, Prerna, Book Review: Indigenous Peoples \& Poverty edited by Robyn Eversole, John-Andrew Mcneish and Alberto D. Cimadamore (September 6, 2010). Available at SSRN: https://ssrn.com/abstract=1672645 or http://dx.doi. org/10.2139/ssrn. 1672645

SUNSERI, Charlotte K. "Capitalism as Nineteenth-Century Colonialism and Its Impacts on Native Californians". Ethnohistory, Volume 64, Numer 4, October 2017. 


\section{8}

STAVENHAGEN, Rodolfo. "Los nuevos derechos internacionales de los pueblos indígenas”. Anuário Antropológico 2007-2008. Rio de Janeiro: Tempo Brasileiro, 2009.

WALLERSTEIN, Immanuel. EI modierno sistema mundial: la agricultura capitalista y los origins de la economía-mundo europea en el siglo XVI. México: Siglo Veintiuno, 1979. v. 1.

WALLERSTEIN, Immanuel. EI modierno sistema mundial II: el mercantilismo y la consolidación de la economía-mundo europea 1600-1750. México: Siglo Veintiuno, 1984. v. 2.

WALLERSTEIN, Immanuel. El modierno sistema mundial III: la segunda era de gran expansión de la economía-mundo capitalista, 1730-1850. México: Siglo Ventiuno, 1998. v. 3.

WARREN, Kay \& JACKSON, Jean (Eds.). Indigenous Movements: Self-Representation and the State in Latin America. Austin: University of Texas Press, 2002.

WOLF, Eric. Europe and the People Without History. Berkeley \& Los Angeles: University of California Press, 2010 (1982).

ZAMOSC, Leon. "Agrarian Protest and the Indian Movement in the Ecuadorian Highlands”. Latin American Research Review, Vol. 29, No. 3, 1994. 